\title{
Author Index Volume 9 (1996)
}

The issue number is given in front of the page numbers.

International Conference on National Medicinal Drug Policies

Statement of the International Working Group on transparency and accountability in drug regulation

Editorial: Time to lift the veil of secrecy

(1) $47-59$

Amschler, U., Drug safety regulations of the 'Drug Commission of the Counties'

(3) $211-217$

(3) $131-132$

(2) $91-93$

Bankowski, Z., The monitoring of drug safety and reporting of adverse drug reactions

Bardelay, D., An ISDB survey to assess the degree of transparency of drug regulatory agencies

Beckmann, J., Drug safety regulations and strategies of the German authority for medicinal products

Beppu, H., The case of contaminated blood products in Japan

Bertelsmann, A., Statutory regulations governing the reporting of adverse reactions

Bixler, E.O., see Kales, A.

(2) $115-120$

(3) $151-155$

(2) $75-81$

(3) $157-159$

(2) $101-106$

(1) $7-27$

Dinnendahl, V., Drug safety regulations of the 'Drug Commission of the German Pharmacists' Dukes, G., Editorial: Drug safety: can more be done?

Dukes, M.N.G., Contaminated Human Growth hormone as a cause of Creutzfeldt-Jakob disease

Dukes, M.N.G., Drug regulation and the tradition of secrecy

(2) $87-90$

(2) $71-73$

(1) $41-46$

(3) $143-149$

Helsing, E., Health promoting policies: strong, weak, ..., and sometimes harmful?

Hemminki, E., see Ollila, E.

Herxheimer, A., Side effects: freedum of information and the communication of doubt

Hodgkin, C., International harmonisation - the need for transparency

(1) $1-6$

(3) $161-172$

(3) $201-210$

(3) 195-199

Jensen, L.P., see Levi, N.

(1) $29-31$

Kales, A., A.N. Vgontzas and E.O. Bixler, A reassessment of triazolam

(1) $7-27$

Lee, R., Drug safety regulations in the CPMP

Levi, N., L.P. Jensen and T.V. Schroeder, Audit of the Danish national vascular database

(2) $107-113$

(1) $29-31$

Medawar, C., Secrecy and medicines

Munter, K.-H., Drug safety regulations of the 'Drug Commission of the German Physicians'

(3) $133-141$

(2) $83-86$

Ollila, E. and E. Hemminki, Secrecy in drug regulation

(3) $161-172$

Razak, D.A., Access to regulatory information in Malaysia - a preliminary study

(3) $179-186$ 
Sammut, M. and C. Savona-Ventura, Petrol lead in a small island environment

(1) $33-40$

Savona-Ventura, C., see Sammut, M.

Schroeder, T.V., see Levi, N.

(1) $33-40$

(1) $29-31$

Tempelaar, A.F., Risk and safety in practice

(1) $65-69$

Tempelaar, A.F., Safety and risk in practice

(2) $121-129$

Thiele, A., The German 'Graduated Plan' - criteria, administration, regulations

(2) $95-100$

Vgontzas, A.N., see Kales, A.

(1) $7-27$

Vrhovać, B., Access to information on drug regulation in the countries of Central and Eastern Europe

(3) $173-178$

Weerasuriya, K., Globalisation of drug regulation and drug regulators in developing countries

(3) $187-193$ 